\title{
Networked learning with user-enriched educational material
}

\author{
V.C. Vescoukis \& S. Retalis \\ Software Engineering Laboratory, National Technical University of Athens
}

\begin{abstract}
The scope and the philosophy of the use of New Technologies in education have still to be defined and important pedagogical issues arise. Based on experience of secondary technical vocational education, a general schema for Network-Based Learning with strong learner participation is proposed. The main concept of this approach is that learner participation in the learning process can produce or at least motivate the production of learning material. A pilot implementation of such an activity produced quite interesting results and indicated that the content of the learning material can be enriched by material produced by the trainees themselves.
\end{abstract}

Keywords: Networked learning; Secondary; Student activities; Technical education

\section{Introduction}

There are two forms of secondary technical education in Greece: Technical Lyceum (TEL) and Technical Schools (TES). These provide 3-year secondarylevel technical education: schools of the TEL-type work during day hours and have students between 15-19 years of age having no professional experience, while those of TES-type work during evening hours and have students aged 17 to 45 with some professional experience. On-the-job training is part of the curricula of both TEL and TES schools. Still, most of the practical experience students acquire is provided through lab-based courses. These courses are conducted in a fully controlled laboratory environment which, of course, has little similarity to the real world.

A similar situation can be recognised in non-technical disciplines. Projects, training research activities, papers, etc. take the place of laboratory exercises and on-the-job training of the technical area. The main qualitative similarity lies in the fact that valuable and possibly further exploitable results are also produced in these activities. In every case, the 'official' educational material that supports such courses and activities is usually in the form of theoretical

Based on a paper selected from the Networked Lifelong Learning Conference, Sheffield University, April 1998

Correspondence: V.C.Vescoukis, Software Engineering Laboratory, Electrical and Computer Engineering Department, NTUA Campus, Zografou, 15780 Greece

Email: V.Vescoukis@cs.ntua.gr 
textbooks. Only in a few cases do trainers unofficially develop ad-hoc case studies, exercises, etc. in order to enhance their teaching. However, these activities are quite localised and are not certified or used effectively and on a regular basis.

It is generally felt that learners are nowadays more mature than they used to be and they can be engaged and trusted to evaluate their learning process. They can also be trusted to contribute to the development of learning material, mostly by putting theory to practice, as is the case in on-the-job training, educational research and homework projects. It is evident that most education has ignored such facts and it has several shortcomings:

- the learning process lacks the mechanisms to benefit from feedback to keep the learning content up-to-date, close to real life and to the mentality of learners;

- much learners' effort that could be used to add value to the learning of future generations is wasted through do-and-forget projects;

- laboratory exercises, home assignments and other related activities should be designed to provide not only better understanding of theory, but also many examples of everyday practice, as seen through the eyes of the learners themselves.

These concepts provided the motivation for this study which was fortunate to have support from an EU-funded project in the area of secondary technical education. As mentioned above, on-the-job training is among the activities undertaken by learners in such institutions and this can be regarded as 'productive learner activity'. 'Productive' means that learners undertake projects, exercises, experiments, etc. which they carry out producing some outcome such as papers, reports, experimental devices etc. These outcomes are presented in the classroom where a discussion about them is likely to take place. However, the most important aspect of these activities is the experience learners acquire beyond that which is achievable in a classroom environment.

As the learning process is repeated in subsequent academic years, many of these activities are repeated from the very beginning. There is no mechanism for the transfer of learner-acquired know-how to the following generations of learners. At the same time, the trainers repeat their courses and find no mechanism to improve the quality of their contribution by providing learners with the opportunity to build on and refine previous work or to deepen their conception of each particular thematic area. It is suggested that the constraints imposed on this procedure by traditional means can be alleviated by the use of network-based learning systems.

\section{Project overview}

The main concept is the exploitation of learners' activities in the production of new learning material. This material can be fed back into the learning system effectively and quickly using a Networked Learning Environment (NLE) as illustrated in Fig. 1.

Some products of learning activities may be regarded as candidate learning materials for an NLE or as the motivation for the development of such material. 
In order to obtain these products, the learning activities have to be planned carefully. Planning includes the creation of material in paper and electronic forms as well as presentations to trainers and other learners. The production of new learning material in this way is done by selecting the best students' products and the content of the NLE is enriched by adding this new material. Of course, the NLE's content can also be enriched in more traditional ways, that is, by materials from other sources.

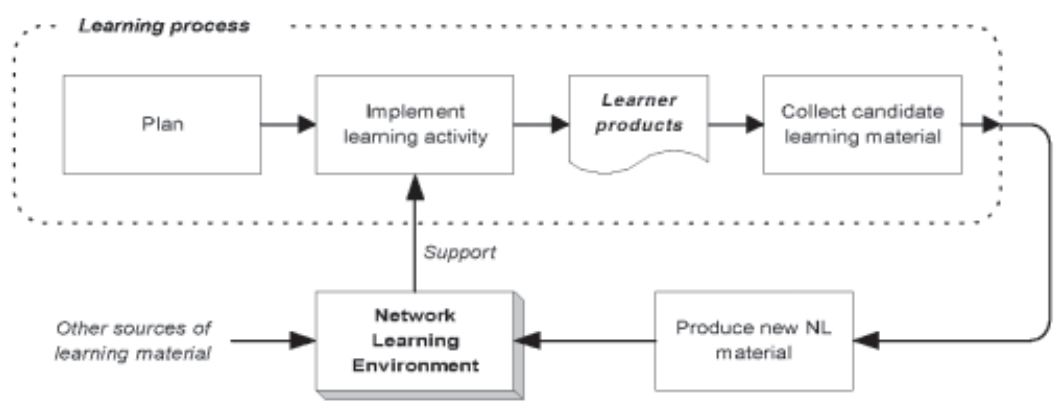

Fig. 1. Recycling learner products to create new NLE material

As can be seen in Fig. 1, the NLE supports but does not replace traditional learning activities (Retalis et al., 1998). It is complementary to the learning process by providing learners with both reference material, interactive exercises, etc. (as is the case in most NLEs) and content produced during their previous colleagues' learning activities. For practical reasons, all such content cannot be discussed in class due to time limitations. However, it is the NLE that plays its role here, allowing learners to have access to lots of examples, case studies, previously carried-out assignments etc. during out-of-class hours. In fact this is a hybrid learning environment with special characteristics in terms of its content sources.

\section{The notion of a hybrid learning environment}

Three factors have been most influential in formulating the idea of a hybrid learning environment: human agents, traditional learning material and process characteristics. The human agents are trainers and trainees. Trainers have to cope with the difficult task of delivering not only new theoretical knowledge, but also ways to exploit this knowledge in everyday activities - not necessarily solely in the area of practising a profession. Trainees need the confidence that they are gaining more than surface knowledge. If the educational system does not inspire this confidence, they gradually lose their trust in the system. Learners over a certain age can and need to participate actively especially in the practical part of training. There are a significant number of cases where they know better than their rusty trainers, what is more useful to learn or where to put the emphasis.

The second factor, traditional learning material, is usually theory-bound and is not much help in putting theory into practice. The working life of learners is a valuable source in determining how they perceive the application of what they learn. Learning material targeted at how-to apply theory in practice is 
actually produced by students during such activities. Finally, the whole learning process takes place in a composite environment: in traditional classes, in labs and in real world work premises. An NLE cannot replace tuition in these locations, but it can be of assistance and support. This is why the term 'hybrid' is considered appropriate for this approach.

In resumé, the main elements of a hybrid NLE are the following:

- Four ways of learning should co-exist: traditional classroom-based teaching, practice in labs and school premises, homework assignments and projects, and activities carried out in the real world (such as research or on-the-job training). All of these should be supported by an NLE and each play a complementary role to the others (Fig. 2a).

- During their educational activities outside the school context, students themselves identify and provide new content to be added to that of the existing NLE which is thereby continuously updated (Fig. 2b).

- The NLE should be accessible to trainers and learners in the preparation and support of their educational activities such as home assignments, papers, on-the-job practice, etc.

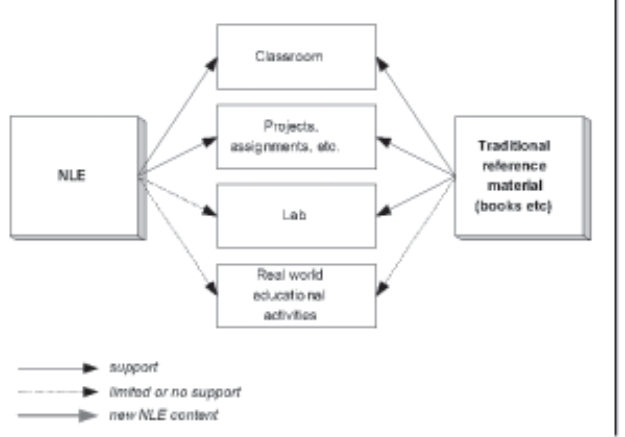

Fig. 2a. A traditional NLE

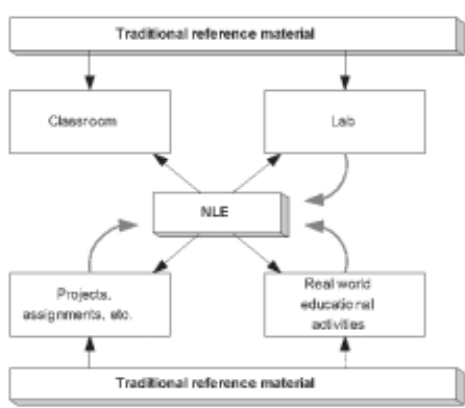

Fig. 2b. A hybrid NLE

A case study where these ideas have been implemented* took place in a secondary-level technical education institution under the support of the Hellenic Ministry of Education operational programme.

\section{A pilot implementation}

Sivitanidios Public School of Crafts and Professions (SCP), is a public institution of secondary-level technical vocational education located close to Athens. One part of the vocational training offered in SCP is on-the-job training which is a specific 'real world learning activity' as discussed earlier. During this activity, students leave classroom-based training and work as trainees in real jobs, having the opportunity to gain experience in a environ-ment where they apply what they have learned in classroom. There is a problem in supporting this learning process since students are not available for classroom discussions during that period of time. Moreover, there is lack of educational material for the students

* This work is supported by the Second Community Framework Program for Education in Greece (EPEAEK). 
to assist them in handling problems that appear on-the-job. The production of learning material as well as the definition of a framework to support this kind of process using networked learning is considered to be a well-established need, as well as a challenge.

A limitation is the existence of a strict and well-defined programme of studies designed for student populations with little diversity, as is the case in SCP. The background of this population comes from classroom and lab. training of practical skills. Although some students may already possess some professional experience, the current practice has no mechanisms for exploiting and disseminating this experience to the rest of the students. It is intended to develop mechanisms in order to turn the outcomes of students' practical experience, both pre-existing and gained during on-the-job training, into useful learning material within an NLE that supports on-the-job training activities as well as the traditional classroom based teaching.

\section{Scope of the networked learning approach}

In the SCP case, on-the-job training activities last two to four weeks and take place once or twice a year in groups of 100-200 participants. During the first week, after students return to the classroom, they examine the possibilities of creating new learning material from the experience gained. During this period, students define the content and provide the material for the development of new learning modules. The development, classification and publication of the new modules on the web server that hosts the NLE, is then assigned to professionals under the supervision of domain and network-learning experts. Members of the teaching staff of SCP with little or no experience in the development of instructional material, are trained to support this process. A critical job they have is the evaluation of the quality of the learning material proposed by students based on quality criteria.

Incremental refinement, a method of software development (Somerville, 1995), is used in the design and implementation of the proposed networked learning approach as shown in Fig. 3. For each technical specialisation area of the students' on-the-job training activity, a four-phase process takes place:

- preparation which includes structuring the reports that will be filed upon completion of the on-the-job training activity;

- assignment of students to companies and 2-4 week practice;

- collection of candidate educational material based on the practical cases experienced by students;

- development of the corresponding networked learning material

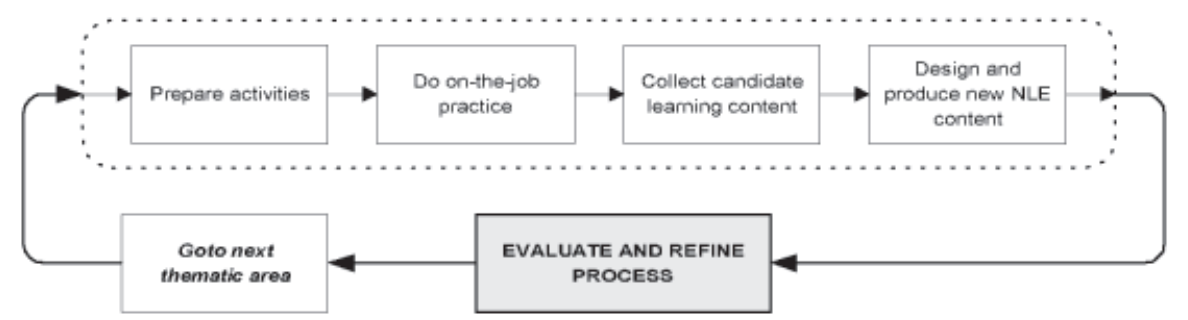

Fig. 3. Developing new learning content using incremental refinement 
The last two phases are supported by experts in the design and presentation of learning material, as well as by professionals who actually do the administration of the NLE. After this 4-phase process is complete, an evaluation of the process itself by instructional developers (ID) takes place, and a refined version (that is, more pedagogically effective) of the material is produced for supporting the learning process of the SCP students. As necessary, the content of material produced earlier iterations is updated.

What makes this approach interesting, is that learning material is produced by students for students. It therefore reflects the way students themselves not some remote authority - conceive their needs and practical experience. Furthermore, the NLE in which this content is added becomes more useful and 'alive' and can be accessed not only by students, but also by other interested parties such as active professionals.

The philosophy of this learning approach draws on two pedagogical principles: learner-centred and case-based learning. The focus of the learnercentred is on the active participation of the learners and on the variety of different means of knowledge transfer and acquisition. Undoubtedly, teachers have the major responsibility for what and how the students learn. However, the students should not be just puppets, passively dancing as their teachers pull the strings (Graziadei, 1997). The educational settings should provide them with access to familiar and easily digestible learning material when, where and how they want it (Laurillard, 1993).

Case-based learning differs from traditional lecture-based learning in the sense that knowledge is not represented as theory but in examples. Case-based learning builds on the idea that human expertise is not comprised of formal structures (like rules), but of experience (Nagendra Prasad, 1995). In addition, the learner can find the solution to a problem by retrieving similar cases from a library and adapting those solutions to the new problem.

\section{Architecture and implementation}

A general overview of the hybrid learning environment is shown in Fig. 4. Traditional classroom teaching provides students with the basic theoretical knowledge required to carry-out laboratory practice. The latter prepares students for on-the-job activities that take place either in local companies or in an experimental enterprise run by SCP, the SCP Technical Assistance Centre (SCP-TA). This is shown by dashed arrows in Fig. 4. Traditional material supports all activities for reference purposes. An NLE provides not only electronic reference material, but also case studies, communication services, etc both for trainers and students (Koutoumanos et al., 1996).

The innovation of this architectural schema lies in the students' ability to trigger the production of new learning material that may be added to the NLE. This material consists of case studies and experience reports that students have experienced while doing their on-the-job practice. Furthermore, the NLE is accessible not only to current SCP students, but also to active technical practitioners of every age. Thus, practitioners have the opportunity to update their technical knowledge not just by using some 'remote electronic book', but by viewing experience reports on current real problems together with suggested 
solutions, related issues, references, etc, authored by other practitioners who actually 'speak the same language'.

As for the NLE itself, at a physical level it is a distributed web-based system that uses the client-server model with all material centrally stored. The clients need not be physically located in the SCP, but they can connect to it through the $\mathrm{SCP}$ network, through the Internet or via a regular phone line.

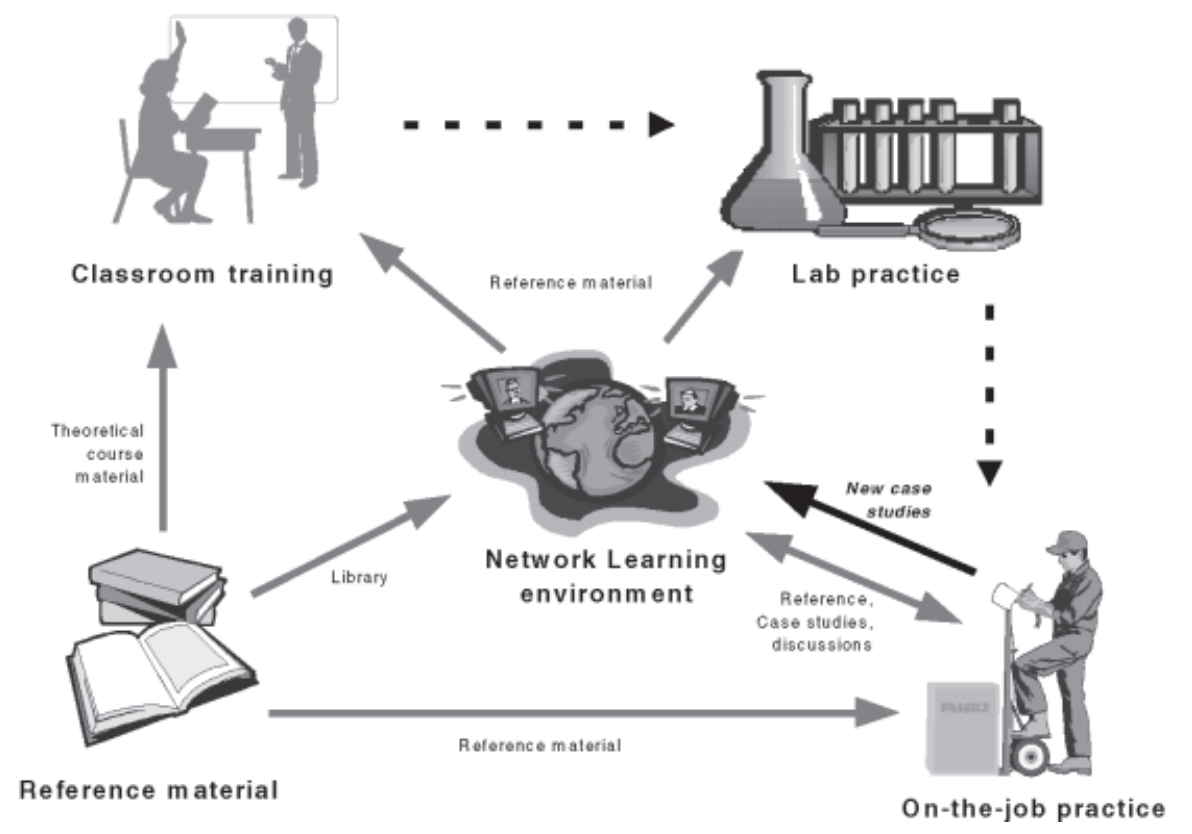

Fig. 4. An architectural overview of the implementation

The main characteristics of the NLE are:

- The environment provides students with a means of submitting questions and the instructor with a means of answering them. It implements a communications channel, in which all students and the instructor participate and discuss matters related to a specific course electronically. The content of the discussions that take place, as well as all questions and answers, can be stored so that they can be reused.

- The educational material in the NLE is widely available and able to be accessed by many clients from many different locations at the same time. It is also hierarchically structured and uses hypertext links in such a way as to facilitate and guide the users.

- The environment facilitates the users in their attempts to locate and access course-related material that is distributed over the Internet.

Its basic design accords with the specification requirements of an NLE used at the National Technical University of Athens (Koutoumanos et al., 1996).

\section{Operation}

How does this environment work in the real world? The flow of student activities is shown in Fig. 5. During the first year, students attend mostly classroom lectures 
supported by the NLE but the balance during the second year turns to lab exercise where they get the basic practical skills to tackle technical problems in a simulation of the real world. During their third year, students become parttime 'staff' of the SCP-TA. As mentioned earlier, SCP-TA is a student venture, the first of its kind in Greece, providing services (home electricians, plumbers, etc) to households located around SCP.

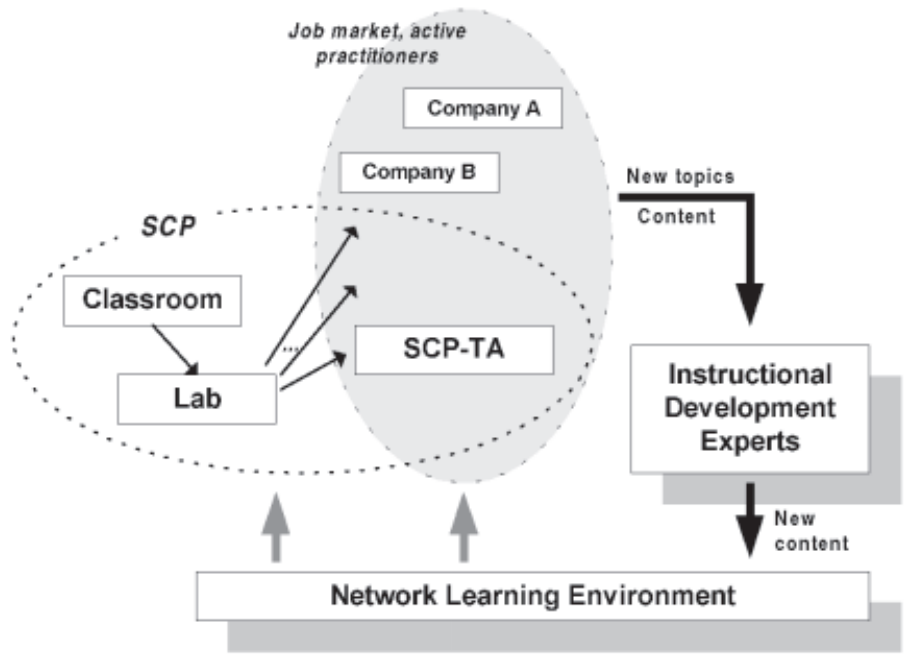

Fig. 5. Student activities in the production of new NLE content

Apart from continuing to attend both classroom and lab, as staff of SCP-TA, students are on-call for clients' requests which are satisfied under the supervision of experienced practitioners. During this process, both students and supervising practitioners have access to the NLE for reference or study of similar cases. For a 2- to 4-week period, students have the option of either becoming full-time staff of SCP-TA, or doing their on-the-job practice in local companies. Upon return to the classroom, students can suggest new case studies to be added to the NLE for which they provide the core content as they have perceived it during their own practice. This learning material is then passed to ID experts who make the necessary modifications, classification and production of the instructional material that will be added to the NLE.

\section{Lessons learned}

The architectural schema of the hybrid learning environment has worked for more than one year in SCP with the participation of more than 800 students from three technical specialties: home electricians, industry electricians and home plumbers. During the same period, the NLE has been under development offering services of reference material provision and group collaboration. Several useful lessons have been learnt. 
Lesson 1. In the beginning, students did not understand the added value of the NLE. They thought that everything they need to know was 'in the box'. It took students at least 2 to 3 months to realise the complementary role NLE plays in this schema. After this had been accomplished 'the ice broke' and a remarkable increase of student interest took place. However, after another couple of months students began to consider the NLE as a source of on-line reference material. Up to that point, no student-triggered case studies had been created and added to the NLE.

Lesson 2. It was after the first on-the-job training activities had taken place that the students' conception of the NLE changed. They came with lots of suggestions for case studies which they considered worth adding to the NLE. There are two points worth mentioning here:

- First, the NLE is no longer considered by students as some 'electronic authority', as is the case of a traditional textbook. It has become a live tool, in the content of which their suggestions are of vital importance.

- Second, although students may have lots of suggestions for new topics, they appear to be weak in classifying and describing their experience in the form of new learning material.

This weakness can be traced backwards either to the structure and documentation of the forms designed to be used by students in writing down the new content, or even to the students' ability to produce good plain text. Nevertheless, this fact has been an important piece of feedback taken into consideration in the design of the next version of the process to be followed in collecting students' suggestions (as shown in Fig. 3). In the first two runs of the 4-step process shown in Fig. 3, the instructional development experts did more work than initially expected.

Lesson 3. After collecting students' experience reports and suggestions, classifying and developing new content, the NLE was enriched not only in quantitative, but also in qualitative terms. Content whose development was triggered by students' practical experience, is a new qualitative attribute of a NLE. Future generations of students have access to useful pieces of accumulated experience, which have been created by a compatible mentality: that of their colleagues.

Lesson 4. Practitioners who have access to the NLE consider the case-studyoriented content more useful than the other services of the NLE. A study of the browsing habits of about 100 SCP graduates who had access to the NLE, showed that they spend more than $60 \%$ of their time in the NLE in browsing through the case studies. It is expected that when this content becomes available though the Internet, the same behaviour will be observed among the frequent visitors to the NLE publicly available pages.

Lesson 5. Tutors who supervise on-the-job training feel that the distance between themselves and the student-learners becomes smaller when learners play such an active role in the learning process. During these very active discussions, tutors approach learners and discover things they could never imagine students could do or think. Some tutors have pointed out that students break the barrier 
of passive reception of knowledge and become active participants in the learning process.

\section{Concluding remarks}

This paper proposes a generic schema for the enhancement of the learning content of Networked Learning Environments using material created or proposed by learners during their activities in the learning process. This learner involvement is seen as a key element in the implementation of network learning schemas. If a network-based system can improve the way people learn things, why not let people feed the system with learning content they regard as useful? Of course the argument stands for learners of above a certain age, who can conceive their role in the learning process as an active one. Although the authors do not claim to be experts in pedagogical issues, it seems amazing that the age threshold for participation is not as high as it may seem at first glance.

A hybrid learning environment has been set up. In this environment traditional classroom-based teaching, laboratory practise, and on-the-job training are supported by a NLE whose content is continuously enriched by learners themselves. This merger of methods in one educational framework seems to be effective. Concerning the use of networked technology, it is found that when network learning is viewed as a tool that plays a complementary role in the learning process, most of its shortcomings disappear, while practically all of its benefits are still evident (Retalis et al., 1998). Concerning the learnercentred approach of the hybrid learning environment, it is seen that students like acting not only as passive entities but also as active constructors of learning material. The new tools that technology has provided allow such experiments to be conducted. Much work has still to be done in order to obtain and evaluate results from several disciplines, however the messages so far are quite encouraging.

\section{References}

Graziadei, W. (1997) Implications for Teaching and Learning: A paperless classroom but NOT a teacherless classroom. http://137.142.42.95/TL/Change.html

Koutoumanos, A., Papaspyrou, N., Retalis, S., Maurer, H. \& Skordalakis, E. (1996) Towards a Novel Networked Learning Environment. Proceedings of the World Conference of the Web Society (WebNet'96). San Francisco, USA.

Laurillard, D. (1993) Rethinking University Teaching: a framework for the effective use of educational technology. Routledge, London.

Nagendra Prasad, M.V., Lesser, V.R. \& Lander, S. (1996) Reasoning and Retrieval in Distributed Case Bases. Journal of Visual Communication and Image Representation, 7, $1,74-87$.

Somerville, I. (1995) Software Engineering, Addison Wesley, London.

Retalis, S., Vescoukis, V.C. \& Skordalakis, E. (1998) Thesis and antithesis on the use of Network Learning Technologies in Higher Education. Proceedings of Networked Lifelong Learning Conference (eds. S. Banks, C. Graebner \& D. McConnell) pps. 1.421.47. University of Sheffield, UK. 